\title{
Decolonising the Discourse of Environmental Knowledge in Settler Societies
}

\section{Deborah Bird Rose}

This essay is devoted to a practical purpose: to open up an area of discursive space by analysing and exposing a set of practices that serve to police certain boundaries of knowledge. The arena is Indigenous people's claims to a tradition of environmental knowledge and ethics that has pertinent contributions to make to debates about environmental crisis. To be totally clear, I am not proposing to adjudicate the legitimacy of given sets of statements; my focus is on the strategies deployed by non-Indigenous scholars in marginalising or outlawing a class of positive statements. In the interest of even-handedness, I offer counter-arguments where they are missing.

Jane M. Jacobs has offered an excellent discussion of the formal limits of postcolonialism, as does Nicholas Thomas in a somewhat different context. Both insist upon what Jacobs calls 'the fantastic optimism of the "post" in postcolonialism'. Their comments are particularly oriented toward settler societies in which the ongoing relationships between settlers and Indigenous people tend to be constitutive of nationhood. As I have argued elsewhere, we settlers, or settler descendants, are the inheritors of the spoils of a dual war: one war was fought against the natives, and one against nature. ${ }^{2}$ I take the term decolonisation to index a dialogical search; new world settler descended people's efforts to inscribe a moral presence for ourselves in our societies can only be achieved in collaboration with the Indigenous peoples whose lives bear the imprint of colonising violence.

Decolonisation poses a particular epistemological challenge. Not only is there no way to theorise in advance how 
decolonisation should or ought to occur but it would morally reprehensible to try to do so. Decolonisation is a form of practice that is worked at and worked out among the peoples and other living things whose lives have become entangled in the violence of colonisation. As a path toward peace, decolonisation must be open to continuing negotiations. To disallow certain classes of stories because they appear to be tainted is already to fail to work toward decolonisation.

Monologue is the narcissistic conversation that the West has with itself, a key feature of which is that the 'other' never gets to talk back on their own terms. Monologue is a practice of power, of course, since it involves silencing the people whose words and thoughts would require a break with selfabsorption. Much of what passes for conversation is actually monologue because it is constructed around a self-other structure such that the 'other' is the absence or reflection of self. ${ }^{3}$ In contrast, dialogue is intersubjective: it is an openended meeting of subjects. Emil Fackenheim articulates two main precepts for structuring the ground for ethical dialogue. ${ }^{4}$ The first is that dialogue begins where one is, and thus is always situated; the second is that dialogue is open, and thus that the outcome is not known in advance. Openness produces reflexivity, so that one's own ground becomes destabilised. Dialogue breaks up monologue; it clears a ground for meeting, generating a place where people can speak on their own terms. It thus requires attentive listening and an open mind. Construed in this way, dialogue is a decolonising practice leading toward unpredictable outcomes.

There is currently a global discussion about ecological crisis, and the need for social and cultural change. Indigenous people intervene in, or are drawn into, these debates as speakers who try to articulate for others their own understandings, some of which may be foreign to many in their audience. Further, representations of Indigenous people's ecological knowledge and land management practices have been pulled into the discourse as objects of scrutiny, judgement and desire. All too frequently, Indigenous knowledge is dragged into monologue by means of an intellectual structure that operates as a trap. 


\section{The trap}

Noble savage or dismal savage, it hardly seems to matter. Both images are dead ends. And yet, they are often wielded as weapons: if a settler descended person says something positive about Indigenous people's ecological knowledge and/ or ethics, one is accused of romanticism or primitivism; if one says something negative, one may be accused of racism. Indigenous people themselves are by no means exempt; they too are accused of romanticism or, alternatively, of cynicism.

The structure of some of the debates about indigenous ecological knowledge and ethics serves to sustain monologue. My argument is that in the forest of ideas there is a path that is defined by Western narratives; and further, that whoever steps off this path is trapped by a form of argument that lands you straight back on the well-trodden path. I will look at the structure and process of how that is done.

A basic question in the literature is: 'were Aboriginal (or other Indigenous peoples) conservationists?' A tremendous amount of the literature touches on this question one way or another, and a lot of it actually is talking about us (settler descended peoples). One answer is 'no'; it is built upon the view that wherever you go in the world people are pretty much the same: they all want to consume and compete, to achieve greater power and comfort. The fact that Aboriginal people had so little destructive impact upon the environment is said to be due to the level of their technology and their low population densities, rather than to any fundamental difference in their worldview. A second answer, of course, is 'yes'. It is built upon the view that there are social and cultural differences among the different families of humanity, and that Aboriginal people have developed systems of knowledge and ways of managing ecosystems that may differ from European-derived management of knowledge and land.

My own view is that one would not want to spend too much time debating this question because it is monological. In asking whether 'our' views are held by others, we go looking for ourselves, we engage with our own reflections, and thus we let ourselves be deflected from the more serious and challenging possibilities to be found in dialogue. In a recent, thorough, and relatively even-handed study, Krech distinguishes 
between conservation and protection, and between ecology and environmentalism. ${ }^{5}$ He concludes that there are points of convergence as well as divergence, and he too wonders if the whole debate may be a red herring. That people go on addressing these issues is proof that there are important issues tangled up here; they demand to be treated seriously because they are part of the power relations that sustain monologue and thus already undermine our efforts at decolonisation.

The trap that is hidden near the path in the forest depends on two stereotypes. One is the Noble (Indigenous) Ecologisthe or she lives in perfect harmony, respects all life, has little or no impact on the environment, and is basically oriented toward conserving the world around him or her. The Dismal (Indigenous) Ecologist, by contrast, is pragmatic, ruthless, and destructive. Only their limited toolkit and their small population numbers prevent them from being just as destructive as Western capitalist colonisers. Let me make it clear that I am not drawing on overtly racist literature here; I refer only to published academically informed work.

The trap, a double-jawed device similar to a double-bind, uses both stereotypes to achieve its effectiveness. First a dualism is asserted that appears to canvass all the relevant options: either-or, one or the other. Implicitly the dualism asserts: not both, and not anything else. Each side of the dualism can be understood as one jaw of the trap. Second, one side of the dualism is rejected, usually on grounds that purport to be factual. Third, with one side rejected, the other appears by default to become the truth of the matter. Fourth, the truthfulness of the remaining side is supported through various appeals to commonsense. These appeals appear to be commonsensical because they are part of broader social narratives surrounding which is a vast amount of implicit social support. They are the 'path in the forest', and the narratives are mutually reinforcing.

On my reading of the literature, the noble savage is the first side of the either-or equation; it is the one to be argued with and dismissed. The dismal savage is the second side, the default position. The commonsense view is based on a theory of progress, and requires accepting an implicit theory of history in which humans progressively extricate themselves from nature through increasingly sophisticated technology. The 
commonsense position thus invokes as human givens progress, technology as a driving force and the will to dominate. These are all highly contested issues, of course, but the cunning of the trap is its dual reinforcement. When the dismal ecologist is left standing in the default position, nobody has to take responsibility for an outcome that disempowers Indigenous people. Arrival at the default can seem to be reasoned and fair because it is based on the arguments presented against the first side of the dualism. Once the default appears as an unavoidable conclusion arrived at through reason, the more contested issues can be left unexamined.

An example will bring this out of the abstract and into the domain of living action. Anthropologist Lee Sackett proposes that there is a viewpoint among members of the public that Australian Aboriginal people are to be emulated as ideal exemplars for conservationists. This ideal depends on an either-or dualism: 'Instead of making it their right and duty to tame and harness the wilderness, they lived in harmony with it.' In Sackett's logic (and he is not alone), all that remains, once harmony is dismissed, is to conclude that Aborigines did try to tame and harness the wilderness (such culturally loaded words!) but failed to make much of an impact. To quote again: 'To the extent that they [Aborigines] were conservationist at all, pre-colonial Aborigines were conservationists by default. Their relatively low numbers and limited tool kit meant their impact was of a different order than that of today's high density, industrialised society." ${ }^{6}$ This excellent trap works with a second dualism that reinforces the first. In the second one, the contrast is between a limited tool kit and a highly industrialised society. The contrast is commonsensical and unarguable; the differences are real, even if their meaning is contentious. This dualism conceals the underlying supposition that we are all just driven by our technology; we go our destructive ways, some of us with more impact than others. The commonsensical proposition that hunter-gatherer societies differ significantly from advanced industrial societies slides effortlessly over a theory of social change that is eminently debatable. There is absolutely no consensus around the idea that worldviews, social change, and systems of ethics are solely driven by technology, but this larger issue is obscured. 
Sackett calls for Aboriginal people to be understood in their own terms rather than in terms of Western stereotypes, but he seems to conclude that Aborigines were 'protoenvironmentalists'.7 This proposal neatly traps Aboriginal people within a narrative of evolutionary progress in which we westerners have long since superseded them.

\section{Dismal or noble?}

Dismal natives are stuck in the downstream of history. They are the backward guys with the little tool kits. This stereotypical native has nothing much to say to us (advanced or postindustrialists), first because he is not really all that different; he is driven by technology but is less effective. Second, he has nothing to say to us because we have superseded him. If we are all in the business of consuming and destroying, nobody does that better than we do.

The other side of the either-or structure is the noble ecological savage. He is frequently signalled by the term 'harmony', and Western scholars are particularly scathing of the idea that Indigenous people live(d) 'in harmony with nature'. Harmony encompasses a complex field of stereotypes and debates. At the most extreme, this stereotype implies Indigenous people have all the answers, that their wisdom is so perfect that all we need to do is adopt it, and that their practices are so perfect that all we need to do is mimic them. The far end of this stereotype views Indigenous peoples as themselves sacred. ${ }^{8}$ The exaggerated position is ridiculous, and yet, people go on addressing it as if it had serious substance. It is so ridiculous that every time a scholar takes it on, he or she cannot fail to score a hit. And every time it is demolished, the dismal guy is left in the default position. The very stridency of the antiharmony arguments suggests that some powerful ideas are being challenged.

\section{Perfect wisdom}

An extravagant harmony theme is that Indigenous people were in possession of a system of complete knowledge that enabled them to behave impeccably in conserving the world around them. This claim is totally at odds with all that we know about human beings generally, and thus would seem to 
position Indigenous people as members of another species. It is also totally at odds with what most Indigenous people say about themselves. There are many contexts in which Indigenous people assert that their knowledge is incomplete; their awareness of the complexity of the interactions among living things assures them that they do not know everything. ${ }^{9}$ In respect of the proposition that harmony means perfection, we have to conclude on both etic and emic grounds that by this definition there is no harmony. We would also conclude that the debate at this level is spurious.

A weaker version takes harmony to mean that Indigenous peoples made no alterations to the environment. This idea has been shown in recent years to be completely false in many parts of the world, as numerous scholars argue without hesitation. Indigenous people's use of fire is increasingly being shown to have promoted biodiversity. In Australia it is now possible to say with certainty that Aboriginal people's land management practices, especially their skilled and detailed use of fire, were responsible for the long-term productivity and biodiversity of this continent. ${ }^{10}$ Similar findings are being made in other parts of the world, including North America. ${ }^{11}$

Cultural fires (fires deliberately set by humans for ecological purposes) impact upon the environment but do not necessarily change environments for the worse. Not surprisingly, then, cultural fires are rarely invoked to clinch anti-harmony arguments.

\section{Megafaunal extinctions}

There is an unresolved debate about how a number of species of large prehistoric mammals became extinct, and one theory is that human agency, that is, overkill, was the main factor. Beginning in the United States in the 1960s, Paul Martin has proposed that in about 11,000 BP (before present) human colonisers from Asia instituted a blitzkrieg across the Americas that in a couple of millennia caused all the megafauna of the Americas to go extinct. ${ }^{12}$ Alternatively, Ward's study of North America comes down very heavily on this overkill theory; the main alternative argument is environmental - that megafauna were caught in changing environments to which they could not successfully adapt. 
Recently a similar theory of extinctions has been proposed in Australia under the label 'future eating'. ${ }^{13}$ Tim Flannery proposes that in about $60,000 \mathrm{BP}$ the first wave of human beings arrived in Australia and instituted a blitzkrieg that annihilated the Australian megafauna. Having made a complete mess of the place, they then set about learning how to work with cultural fires and to sustain what was left. Lesley Head shows that current evidence offers almost no support for this position, though there is good evidence to suggest that some megafauna lived on until about 28 ,00o BP. ${ }^{14} \mathrm{Her}$ subtle analysis leads her to conclude that Flannery's thesis 'is partial, deterministic and incompatible with the best evidence currently available'. ${ }^{15}$ David Bowman and David Choquenot have also disputed the 'future eaters' theory, modelling predator-prey relationships in a hypothetical north Australian savannah and concluding that for Aborigines to have killed off the megafauna they would have had to have had far greater population densities than they did in 1788 , or have been far more efficient hunters than they were for the period in which we have direct evidence. ${ }^{16}$

There are two points that bear directly on the use of the overkill theory in anti-harmony arguments. The first is that we do not know why the Pleistocene mammals (or earlier life forms) became extinct, or even if that is what happened to all of them. The evidence is not all in, and a hypothesis cannot stand as a clinching argument against 'harmony' or against anything else. One simply cannot rest one's case on the hypothesis that there may have been a blitzkrieg, but that is exactly what some scholars do. Thus, for example:

Certainly we have something to learn from contemporary tribal peoples, but we must not romanticize them ... those who assume that prehistoric tribes must have existed in some blissful harmony with nature must reckon with the fact that, thousands of years ago, members of such tribes apparently hunted to extinction many large mammals in North America. ${ }^{17}$

This is a fairly blunt operation of a trap that wants to hold out a possibility of conversation even as it snidely undermines the 
ground for dialogue. A more subtle approach is to slide this question into a further dualism. Thus, for example, archaeologists White and O'Connell state:

If the extinction of some Pleistocene species was wholly or even partly the result of human action, then we cannot so easily think of these people as careful environmental managers with a very long-term perspective. Rather, like other humans, they may have been only working for shortterm gains, without considering the long-term effects. ${ }^{18}$

This argument acknowledges the hypothetical quality of overkill theory, and then advances certainty through the use of another dualism. The argument takes no notice of the anthropological literature that examines the interplay between short-term and long-term strategies as complementary, not dichotomised, options in subsistence strategies among many hunter-gatherer groups. ${ }^{19}$ Indeed, the mounting evidence for the effects of cultural fires suggests that people did make, and still today do make, many long-term decisions. Likewise, the widespread existence in Aboriginal Australia of 'sacred sites' that were taboo for hunting and were also refugia and breeding grounds for different species of animals suggests long-term considerations. ${ }^{20}$

The second point goes in another direction. What if people 11,000 years ago, or 60,000 years ago, did hunt animals to extinction? Would that have a bearing on the worldview and practices of people today? It seems to me that it can only have a bearing if one assumes that Native Americans or Indigenous Australians today are identical to their ancestors; that is, if they have not changed at all. ${ }^{21}$ It is dubious to posit such a lack of change, but in this instance the proposition is completely contradicted by further evidence. If overkill is the benchmark for human impact, one then has to account for the fact that there were no major extinctions between the time of the early ones and the period of European colonisation. It would seem to follow that Indigenous people today may know a lot about how to avoid driving animals to extinction. 


\section{Waste and litter}

A second stereotype that is used to clinch the argument against harmony with nature is 'waste'. It cuts across ancient extinctions and current practices, and links up with another current clincher: 'litter'. Waste can be understood as the wastage of 'resources', such as might be evidenced by overkill. In contemporary contexts, waste seems to involve leaving lots of dead animals and other 'waste' lying around; it is thus treated as ecologically, morally and aesthetically repugnant. For example, Sackett takes up the issue of waste, quoting Strehlow's account of Aranda people's reaction to the profusion of edible animals and plants in the wake of drought-ending heavy rains. The Aranda people live in Central Australia and are well accustomed to periods of extreme aridity and periods of well watered abundance (at least by desert standards), apparently linked to the large cycles of El Niño. Strehlow observed Aranda people in a period of abundance following upon a drought, writing that:

Animals were slaughtered ruthlessly, and only the best and fattest parts of the killed game were eaten; every tree was stripped bare of its fruits, and all that were unripe and tasteless were tossed away with that air of wasteful carelessness that characterizes the improvident native whenever a brief spell of material abundance smiles upon his hard lot. ${ }^{22}$

Strehlow's judgmental description is of the dismal guy - ruthless, careless and improvident-but, in my experience with Aboriginal people, leaving food on the ground does not constitute waste. Food not consumed by humans will be consumed by others, and it is not wasteful to leave food for them. It is most common indeed for people to take the best parts of the meat for themselves and to leave the remainder for the dogs. Other meat-eaters such as dingoes and raptors also benefit, as do the ever-present meat ants. I do not know what he means by 'ruthless slaughter', but in non-judgmental terms one would say they were responding how living things respond to abundance following deprivation: they build themselves up. 
I am not acquainted with the type of harvesting that strips trees bare, but I am well acquainted with the type of eating that seeks the most delightful fruits, and leaves the rest for others. As my friend and teacher Jessie Wirrpa told me when we were on walkabout getting conkerberries, 'turkey will eat 'im, emu might eat 'im, dingo can eat 'im too, even goanna might eat 'im'. The food we left was going to be put to good use by the other creatures with whom we shared those places and those foods.

The use of litter as a clinching argument falls more readily into the category of racism than reason, ${ }^{23}$ but may also be a source of genuine perplexity. ${ }^{24}$ The category of waste easily slips into litter, but it is useful to distinguish between the two because litter is currently a concern of its own and rests on quite different cultural suppositions. According to an Australian state government report on litter control, litter is defined as waste improperly discarded. ${ }^{25}$ The particular emphasis is on public places such as roadsides, beaches, parks and vacant lots. A problem of waste disposal, with effects on resource conservation and public health, the same report states that 'the primary impact of litter is aesthetic'. The general view is that litter 'is visible evidence of antisocial behaviour' and that 'littering is a behavioural problem'.

I hold no brief for litter. It is a serious problem everywhere. What interests me, however, is that ideas about litter and litter control invoke some fundamental propositions about civil society: about the difference between public and private space, about what constitutes good citizenship. Consider the idea that a good citizen picks up after herself. Her social responsibility is demonstrated as she erases the traces of her presence.

My Aboriginal teachers in the Northern Territory rarely picked up after themselves, but more to the point, they never seek to erase themselves. When they go fishing they call out to the ancestors and Dreamings saying 'Give us food, the children are hungry, we got kids here!' When they get food, they cook it on the spot. The remains of people's action in country tell an implicit story of knowledgeable action: these people knew where they were, they knew how to get the food that is there in the country. The country responded to their presence by providing for them. Anti-social behaviour, in contrast, 
involves sneaking around the country, not announcing one's self, and using special techniques to avoid leaving tracks or traces. It is the behaviour of people who intend harm or who have something to hide. Self-erasure is anti-social; visible and audible presence is responsible and moral.

In sum, none of the three main arguments brought to bear in contending that Aboriginal people did not live in harmony with nature - extinctions, waste and litter-go to prove what the authors claim them to prove.

\section{Natural natives}

There is yet another argument: it works against the idea that Indigenous people lived in harmony with nature because they were part of nature. Many Western scholars hold this idea to be racist because it conflates biology with culture. ${ }^{26}$ The claim of racism is based on the Western distinction between nature and culture, and on the long and miserable history of colonisation during which Aboriginal people were treated as a part of 'nature' by people who held both nature and natives in contempt. The logic in this argument is that because Aboriginal people are human, and because humans are part of culture, not nature, then Aboriginal people cannot be part of nature. If harmony means that people are part of nature, then there is no harmony.

It is now well known that the distinction between nature and culture is a cultural artefact itself. We have an excellent body of ecofeminist analysis, as well as the critical theory of a number of postmodern and postcolonial streams, in addition to a newer anthropological stream that demonstrate the ethnocentricity of the belief that human culture is separated from, and is in some sense superior to, nature..$^{27}$ The story that Western civilisation tells about itself is the story of culture transcending nature.

For many Indigenous people, though, knowing that one is part of nature constitutes wisdom and law. My friend Riley Young Winpilin, like many Aboriginal Australians, believes that Law comes from the earth, and he holds this to be a matter of high regard: 
You can't change ... that big hill there. You can't change im this ground. How you going to change im? How you going to change that creek? .. You can't. No way! ... I know government say he can change im rule. But he'll never get out of this ground. ${ }^{28}$

He is saying that human projects properly conceived will be embedded in 'this ground'. It is unjustifiable to suggest that he does not know what he is talking about. To universalise the culture/nature binary is to assert that Indigenous people who believe themselves to be embedded in the world around them must be rescued from their own lack of understanding. Such a rescue mission is itself a colonising project.

Along with people's assertions that they are part of nature, many Indigenous people also assert that they do or did live in harmony with nature. This perspective may be ridiculed by any of the arguments above, or it may be dismissed as romantic fantasy or nostalgia. The term harmony is most frequently undefined by Indigenous people, but it often conveys an idea of peace: they do not see themselves to be in any way at war with their world. As Joe Mohawk said, they do not aim to conquer, or to subdue, or to dominate. ${ }^{29}$ Richard Nelson, in his brilliant study of Koyukon ecological world, says: 'the interchange between humans and environment is based on an elaborate code of respect and morality, without which survival would be jeopardised'. ${ }^{30}$ People seek to live in balanced reciprocity with their ecosystems, rather than trying to 'deplete, despoil and depart', as is said of whitefellas. ${ }^{31}$

If harmony is taken to mean something like sustainable reciprocity, then the evidence from many sources indicates that many Indigenous peoples understand themselves to live this way. Furthermore, the evidence of their interactions with ecosystems prior to colonisation supports the accuracy of their view. So too does the evidence of many anthropologists whose work during the past six or more decades has shown that 'egalitarian hunter-gatherers and horticulturists cultivate an ethic of environmental responsibility'. ${ }^{32}$ This is not a recent anthropological invention, although some critics would like to maintain that it is. 


\section{Ecological racism}

Joe Mohawk, a Native American professor of social philosophy, uses the term 'ecological' racism to describe the imperialistic view that everybody in the world is called upon to go out and assert 'dominion over nature'. ${ }^{33}$ Mohawk argues that the imposition of the theory of a universal drive for domination is hegemonic and violent. This intellectual imperialism denies the possibility that Indigenous or other peoples have things to say to us advanced capitalists. It denies that we could listen and learn, that we could talk back and be answered, that our conversations could be beneficial to all of us. The most extreme instances are quite clearly part of the Indian-hating stream of American social life, and would be labelled racist in Australia as well. The moderate examples I have discussed do not work on hatred in any overt sense, and yet they do invoke the kind of hegemony that Mohawk identifies.

Their power to police the discourse is, I believe, intimately associated with the West's monological history of its own superiority. As is well known, many of the racial tropes of colonisation invoke exactly the images of waste, carelessness and ruthlessness that I have discussed above. Hawkins makes an important contribution to this strand of analysis by proposing that current moves to control litter and waste constitute a process of virtue-adding. ${ }^{34}$ This analysis heightens the colonising contrast, discussed by Anderson in his essay on 'excremental colonialism', between the closed and bounded American (white) body and the open, grotesque (undisciplined) body of the colonised other (Filipino, in Anderson's case study). ${ }^{35}$ The deeply internalised regulatory discipline of Western selves is caricatured in this contrast, even as it seeks to repress and reform the other.

The particular point I wish to pursue here concerns virtue. We can turn Hawkins's analysis back into colonising power relations where natives have been imagined as lacking virtue. Here again the dismal native appears in the downstream of history, this time as a virtue deficit. As a wastrel and a pollutant, he becomes an actual hindrance to good environmental management. Russell Barsh, for example, says that Indigenous people 'must not only pay attention to what can be learnt from their past, but adopt realism about their present'. 
His concern for realism is used against Indigenous leaders because he believes they are self-deluded in thinking that they already have values and beliefs that can fruitfully inform and shape their actions, and that are relevant in today's world. ${ }^{36}$

I think we can turn Hawkins's analysis back into scholarly practice as well. The stridency of much of the anti-harmony arguments may arise from the possibility of our own scholarly virtue being either impugned or rendered irrelevant. Harmony is a value-laden and virtue-bearing term. The idea that virtuedeficient people lived in harmony with nature must suggest either that our own understandings of history are faulty, or that there is such a thing as harmony without (our kind of regulatory) virtue. The spectre of a natural or undisciplined harmony is, of course, one of the West's dreams, desires, and stereotypes. It also conjures anxiety. What if the disciplines we practice on ourselves and others are both unnecessary and ridiculous? Anti-harmony arguments may contain a desire to salvage a story of our own self-discipline as well as a theory of (our own) history. They would thus salvage the meaning of the actual practices of our daily lives. It is necessary to remember, therefore, that monologue works with absence. If 'our' virtue is not visibly present, then, from a monological perspective, there is no virtue. If 'our' disciplines are not present, then there is no discipline. Scholars who reject the idea that Indigenous people have anything of substance to contribute to ecological knowledge are not saving Indigenous people from stereotypes; they are saving their own monologue.

\section{So what?}

Thomas makes the excellent point that the business of simultaneously exhibiting and exterminating natives is part of the enduring invasive logic of a settler-colonial nation. ${ }^{37}$ Philip Deloria makes a similar point concerning the United States: that American (settler) identities are 'built not around synthesis and transformation, but around unresolved dualities themselves'. Those dualities include the simultaneous desire to exalt and 'extirpate' the Indian. ${ }^{8}$ The Noble and Dismal savage stereotypes are deployments of power toward this dual project. One exalts by appropriation, the other extirpates by dismissal, and both efface the living people who are targeted 
by the stereotypes. Each in its own way invites parody, trivialisation and, ultimately, contempt. Consider, for example, Thomas's concerns about primitivism: 'In the environmental movement [in Australia], and in the Green consciousness that has spread well beyond lobby and activist groups, Aboriginal uses of land and resources are idealised as non-destructive and caring, in contrast with white society's inability to restrain its extractive rapacity.' ${ }^{3} 9$

Thomas mounts a brilliant argument against primitivism, his point being that primitivism merely inverts the hierarchies of modernity, and thus remains trapped within the same binary. I find his analysis to be rich with insight concerning colonialism, but it still has the potential to leave us in monologue. Where is the discursive ground for assertions concerning matters that are not derived from the binary of modernity but that can be (and so amazingly readily are) read through the lens of that binary? Where, for example, is the ground for asserting an ethic of care, or of non-destructive practices, once the proposition has been claimed as a form of primitivism? To put it another way, if there is a commitment to a plurality of positions, as there must be if dialogue is to proceed on ethical ground, then that plurality must be capable of including indigenous people's own positive views concerning their relationships to place, 'nature', other species, and history.

In the midst of these debates, we are in a period of deeply serious questions about resource management: who has the right to be involved in decisions about the use and/or conservation of plants, animals, soils and water? In the twenty-first century these are key struggles nationally and globally, and, as many commentators note, the wars of the future will be resource wars. The project of decolonising our settler homelands cannot be accomplished without due attention to environmental ethics and a re-imagining of the decisionmaking process in respect of environments and resources.

In Australia much of the contestation now focuses on native title issues. If Aboriginal people are found still to be in possession of original (native) title, they will legally occupy a place in decision-making, and the decisions are of huge long-term magnitude. Native title cases are vigorously opposed. The Yorta Yorta case, with which I was involved, pitted 
a group of Aboriginal people ('Yorta Yorta') against some five hundred opposing parties (some of whom dropped out, and many of whom pooled their efforts), including three state governments. When Yorta Yorta people asserted that their relationship to country is demonstrated by the fact that they take care of the country, the opposition contested this point of view.

Olney J. heard the case and decided against the Yorta Yorta applicants. His decision was appealed twice and upheld both times. Olney J. took his analysis back to the work of Edward Curr, who had been a squatter in Yorta Yorta people's country. Over the years he became interested in compiling a natural history of Aboriginal people, and he published his Recollections of Squatting in Victoria in 1883. Curr asserted that the local Aboriginal people were lacking in thrift, foresight and reason, writing that: 'food was plentiful, and they were very wasteful of it. I have often seen them, as an instance, land large quantities of fish with their nets and leave all the small ones to die within a yard of the water'. $4^{\circ}$ Olney used this passage as one measure of the lack of continuity in Yorta Yorta traditions when contrasted with the practices of today:

Another contemporary practice which is said to be part of the Yorta Yorta tradition is the conservation of food resources ... It is said by a number of witnesses that consistent with traditional laws and customs it is their practice to take from the land and waters only such food as is necessary for immediate consumption. This practice, commendable as it is, is not one which, according to Curr's observations, was adopted by the Aboriginal people with whom he came into contact and cannot be regarded as the continuation of a traditional custom..$^{41}$

As an anthropologist, it is perfectly clear that Curr observed people who were obtaining surpluses, as people did and do all over the country. His fragment of information, offered as a benchmark of savagery, is almost certainly incomplete. Much of the evidence went like this: Curr's propositions were held as benchmarks, and Yorta Yorta people of today were found wanting. The opposition had argued that Aboriginal people 
traditionally did not take care of country, so any care they engage in today is a new age invention rather than a continuity of their own law and custom. Both Strehlow and Sackett were cited for their anthropological expertise on this point. I imagine that neither would have wanted their work used in this way, as both have been strong supporters of Aboriginal rights, but in the politics of identity and dispossession their twentieth-century scientific authority appeared to confer a continuing legitimacy on Curr's reported observations.

Such debates are the raw material of contestations over who will have land and who will not, who will make managerial decisions and who will be excluded. They are thus contestations about who will control the future of many ecosystems. They will determine which species will live and which will die, which forests will stand, which rivers will run clean, and whose soils will remain uncontaminated. Decolonisation proceeds as a social project when dialogue between settlers and Indigenous peoples is open and attentive across both environmental and social justice. Joe Mohawk put these issues in succinct and elegant form:

It is possible for the first time to take all the knowledge of the whole family of humanity and start plotting a course toward a viable future ... It at last is possible, in other words, not only to finally find the real meaning of Columbus, but to bury it. ${ }^{42}$

In Australia, my teacher Hobbles Danayarri made a remarkably similar argument:

You know Captain Cook been passed away now ... Right, now - till we can have a friend, friend together now. I'm speaking on now. We're friends together because we own Australia every one of them no matter who white and black. We come together join in ... That be all right. Make it more better out of the, out of that big trouble. You know before, Captain Cook been making lot of cruel you know. Now these days, these days we'll be friendly, we'll be love mijelb [each other], we'll be mates. That be better, better for make that trouble. ${ }^{43}$ 


\section{Reflection}

Earlier this year (2014) I had a Skype session with a group of students at the University of Washington in Seattle. They were studying my book Country of the Heart: An Indigenous Australian Homeland, and they had questions and comments that we wrestled with most enjoyably. In spite of the distance between Sydney and Seattle, there were a lot of mutual concerns to talk about. One of the First Nations students asked about romanticism: how do you avoid being dismissed as romantic?

I was struck all over again with the power of this label and its capacity for hurtfulness, especially for Indigenous people who may be pushed to feel constrained in how they understand and present the knowledge of their own elders. It was a pleasure to be able to suggest that she read this essay, and that she start to think of the term 'romantic' as weapon for stifling debate rather than a serious and considered critique.

At the time that I wrote this essay I had two particular stimuli. The first was the fact that while I was a research fellow at the ANU's North Australia Research Unit I had begun to have some significant interactions with biologists. Some biologists were interested in collaborating with an anthropologist, but a few of my fellow researchers were also notable for their dismissive ridicule and, sometimes, hostility. Being laughed at for suggesting that Aboriginal people should be involved not only in the conduct of research but in the very design of the research questions was unpleasant. These understandings, which are almost taken for granted today, were provocative in the early 1990 os in north Australia. Being an anthropologist, I became interested in the cultural context which made dismissal and ridicule seem reasonable.

In those same years, I was flying to Melbourne regularly to work with the Yorta Yorta people on their native title claim. I was a senior off-sider (the 'grey beard', had I happened to have one!) while their main anthropologist was Rod Hagen. It was a shock to read Justice Olney's findings in the matter; once again the idea that Indigenous people could be experts concerning their own lives was being radically and harshly dismissed. I embarked on a series of articles in which I explored how a refusal to listen to Aboriginal people was normalised in academic and other texts. This essay was part of that exploration.Life goes on: Aboriginal people's involvement in ecological research in north Australia is now well 
established. The Yorta Yorta people have found alternative routes toward inclusion in the care of the River Murray. ${ }^{44}$

\section{Notes}

Jane M. Jacobs, Edge of Empire: Postcolonialism and the City, Routledge, London, 1996, p. 24.

Deborah Bird Rose, 'Social Justice, Ecological Justice, Reconciliation' in Lenore Manderson (ed.), Reconciliation: Voices from the Academy, Occasional Papers of the Academy of Social Sciences in Australia, no. 2, 1999, pp. 30-9.

Deborah Bird Rose, 'Indigenous Ecologies and an Ethic of Connection' in N. Low (ed.), Global Ethics for the 21st Century, Routledge, London, 1999, pp. 175-86.

Emil L. Fackenheim, To Mend the World: Foundations of Post-Holocaust Jewish Thought, Indiana University Press, Bloomington, 1994, p. 129.

Shepard Krech, The Ecological Indian: Myth and History, W.W. Norton \& Company, New York, 1999.

Lee Sackett, 'Promoting Primitivism: Conservationist Depictions of Aboriginal Australians,' Australian Journal of Anthropology, vol. 2, no. 2, 1991, p. 239. Ibid., p. 240.

Bron Taylor, 'Resacralizing Earth: Pagan Environmentalism and the Restoration of Turtle Island', in D. Chidester and E. Linenthal (eds), American Sacred Space, Indiana University Press, Bloomington, 1995, p. 119.

Calvin Martin, Keepers of the Game: Indian-Animal Relationships and the Fur Trade, University of California Press, Berkeley, 1978, p. 187; Colin Scott, 'Science for the West, Myth for the Rest? The Case of James Bay Cree Knowledge Construction', in L. Nader (ed.), Naked Science, Anthropological Inquiry into Boundaries, Power and Knowledge, Routledge, New York, 1996, p. 73.

See Stephen J. Pyne, Burning Bush: A Fire History of Australia, Holt, New York, 1991.

For example, Henry Lewis, 'Fire Technology and Resource Management in Aboriginal North America and Australia', in N. Williams and E. Hunn (eds), Resource Managers: North American and Australian Hunter-Gatherers, Aboriginal Studies Press, Canberra, 1982; Krech.

Peter D. Ward, The Call of Distant Mammoths: Why the Ice Age Mammals Disappeared, Springer, New York, 1997, p. 162.

Tim F. Flannery, The Future Eaters: An Ecological History of the Australasian Lands and People, Reed Books, Melbourne, 1995.

Lesley Head, 'Meganesian Barbecue: Reply to Seddon', Meanjin, vol. 54, 1995, pp. 702-9.

Ibid., p. 706.

David Choquenot and David Bowman, 'Marsupial Megafauna, Aborigines and the Overkill Hypothesis: Application of Predator-Prey Models to the Question of Pleistocene Extinction in Australia', Global Ecology and Biogeography Letters, no. 7, 1998, pp. 167-8o.

Michael Zimmerman, 'Rethinking the Heidegger-Deep Ecology Relationship', Environmental Ethics, vol. 15, 1993, pp. 208-9.

Quoted in Sackett, p. 237.

9 See James Woodburn, 'Hunters and Gatherers Today and Reconstruction of the Past', in E. Gellner (ed.), Soviet and Western Anthropology, Duckworth, London, p. 1980 .

See for example A. E. Newsome, 'The Eco-Mythology of the Red Kangaroo in 
Central Australia, Mankind, vol. 12, no. 4, 1980, pp. 327-34.

21 See Christopher Vecsey, 'American Indian Environmental Religions', in C.

Vecsey and R. Venables (eds), American Indian Environments, Ecological Issues in Native American History, Syracuse University Press, Syracuse, 1980.

22 T. G. H. Strehlow, Aranda Traditions, Melbourne University Press, Melbourne, 1947, pp. 49-50.

23 For example, Martin, p. 162.

24 For example, Dougas Buege, 'The Ecologically Noble Savage Revisited', Environmental Ethics, vol. 18, 1996, p. 8o.

25 Litter Control Committee of the Australian Environment Council, 'Report on Litter Control', in AEC Report No. 8, Australian Government Publishing Service, Canberra, 1982, p. 3.

26 Chris Anderson, 'Aborigines and Conservationism: The Daintree-Bloomfield Road', Australian Journal of Social Issues, vol. 24, no. 3, 1989, p. 220.

27 Paul Faulstich, 'Geophilia', Wild Earth, vol. 8, no. 1, 1998.

28 Quoted in Deborah Bird Rose, 'An Indigenous Philosophical Ecology: Situating the Human', The Australian Journal of Anthropology, vol. 16, no. 3, 2005, p. 57.

29 Joe Mohawk, 'Looking for Columbus: Thoughts on the Past, Present and Future of Humanity', in M. Jaimes (ed.), The State of Native America: Genocide, Colonization and Resistance, South End Press, 1992, p. 442.

30 Richard K. Nelson, Make Prayers to the Raven: A Koyukon View of the Northern Forest, University of Chicago Press, Chicago, 1983, p. 31.

31 Donald A. Grinde and Bruce Johansen, Ecocide of Native America: Environmental Destruction of Indian Lands and Peoples, Clear Light Books, Santa Fé, p. 274.

32 Scott, p. 85.

33 Mohawk, p. 442.

34 Gay Hawkins, The Ethics of Waste: How We Relate to Rubbish, Rowman \& Littlefield Publishers, Lanham, MD, 2006, p. 9.

35 Warwick Anderson, 'Excremental Colonialism: Public Health and the Poetics of Pollution', Critical Inquiry, no. 21, Spring 1995, pp. 640-69.

36 Barsh, 'Indigenous Peoples, Racism, and the Environment', pp. 730, 729.

37 Nicholas Thomas, 'Home Décor and Dance: The Abstraction of Aboriginality' in In Place (out of Time): Contemporary Art in Australia, Museum of Modern Art, Oxford, 1997.

38 Philip Joseph Deloria, Playing Indian, Yale University Press, New Haven, 1998, p. 4 .

39 Nicholas Thomas, Colonialism's Culture: Anthropology, Travel and Government, Melbourne University Press, Melbourne, 1994, p. 28.

40 Edward M. Curr, Recollections of Squatting in Victoria, Then Called the Port Phillip District (from 1841 to 1851), G. Robertson, Melbourne, 1883, p. 263.

41 Members of the Yorta Yorta Aboriginal Community V the State of Victoria \& Ors, 1606 Federal Court of Australia, para. 123 (1998).

42 Mohawk, p. 443.

43 Quoted in Rose, 'An Indigenous Philosophical Ecology: Situating the Human', pp. 195-6.

44 MLDRIN (Murray-Lower Darling Rivers Indigenous Nations) is an outstanding organisation whose work and ongoing challenges are discussed in Jessica Weir, Murray River Country, Aboriginal Studies Press, Canberra, 2009. 